\title{
PARQUE URBANO
}

URBAN PARK

FERREIRA, Liz Ivanda Evangelista Pires

E-mail: lizivanda@gmail.com

Palavras-chave: Parque urbano, margem do rio, áreas verdes.

Key words: Urban park, green áeas, river banks.

\section{1 - Temática}

Urbanismo.

\section{2 - Exposição do tema}

Requalificação de um espaço urbano localizado à margem da avenida Raul Lopes (ver figura 1).

\section{3 - Título: Parques das Artes Beira Rio}

No Brasil, cidades como o Rio de Janeiro e Curitiba contam com órgãos eficientes que gerenciam e mantém sistemas de espaços públicos ou de áreas verdes para lazer, mas a maioria dos centros urbanos de médio e grande porte não possui órgãos com essa finalidade. Desta forma, a idéia é que o Parque Urbano de Teresina neste projeto seja público, porém com uma parceria com iniciativas privadas, para efeito de conservação de alguns equipamentos que requerem manutenção mais onerosa, bem como para a exploração se alguns serviços comerciais que se julguem necessários.

\section{4 - Problema da pesquisa}

Teresina é uma cidade com grandes potencialidades naturais. $\bigcirc$ fato de estar localizada entre dois rios proporciona uma umidade que de certa forma ameniza o clima quente e seco da região. Soma-se a isto o fato de possuir uma boa quantidade de espécies vegetais arbóreas, que sombreiam e são capazes de produzir um micro-clima mais agradável.

Possuímos na cidade muitas áreas de preservação ambiental, muitas delas nomeadas por "parques ambientais". São áreas destinadas à preservação das espécies naturais existentes, como o próprio nome diz, e também de lazer contemplativo. Todos esses parques ficam localizados nas margens dos rios, aliás, o próprio conceito de parque ambiental em Teresina se refere a uma área de preservação que, pela legislação municipal, se localiza às margens dos rios. São áreas intocáveis, apenas de preservação, sem nenhuma estrutura que proporcione à população alguma forma de lazer recreativo. No entanto, o que podemos perceber é que a definição de parque ambiental vai mais além, objetiva prioritariamente a conservação desse ou daquele recurso ambiental, como um banhado ou um bosque e, paralelamente possui áreas muito concentradas voltadas para atividades de lazer contemplativo ao lado de áreas voltadas para o lazer ativo. Ou seja, um parque ambiental não necessariamente deve-se limitar à preservação natural e integral dos espaços. 


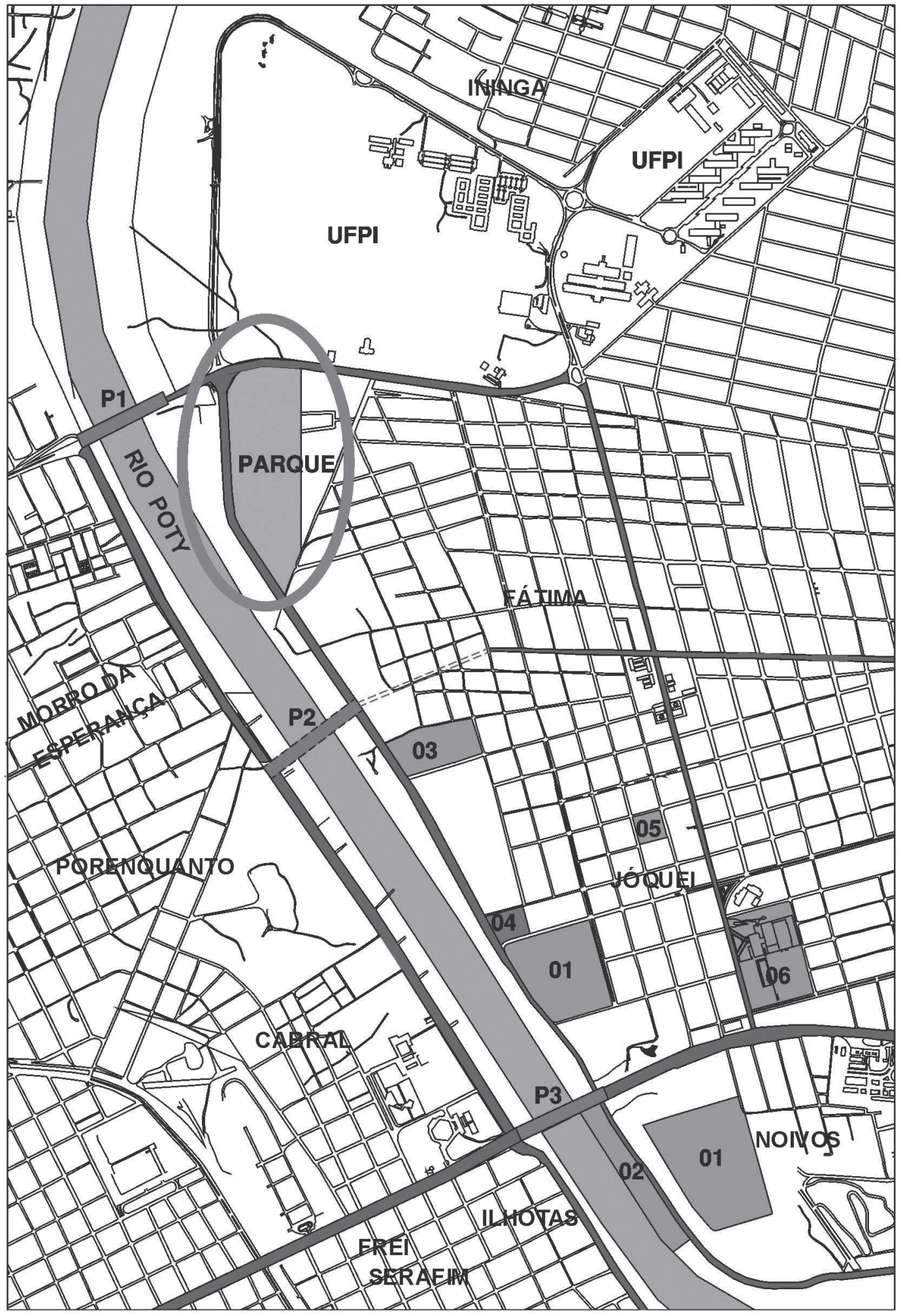

\begin{tabular}{|c|c|c|c|}
\hline $\begin{array}{l}\text { TERRENO DO } \\
\text { PARQUE PROPOSTO }\end{array}$ & PRINCIPAIS VIAS & 02 - PARQUE POTIC ABANA & 05 - PRAÇADO SKAT \\
\hline RIO POTY & ÁREAS DE LAZER & 03 - QUADRAS TÊNIS & 06 - JOCKEY CLUB \\
\hline PONTES & SHOPPING CENTER & 04 - EUROBUSINESS & \\
\hline
\end{tabular}

Figura 1 - Mapa com parte da região leste de Teresina, evidenciando o terreno proposto para o projeto 


\section{5 - Justificativa}

\section{Importância dos parques}

Atualmente, os parques urbanos apresentam inúmeras funções e contribuem para a sustentabilidade urbana. $O$ ambiente natural e agradável desses espaços oferece minimização dos problemas das cidades e traz benefícios para seus habitantes. Além dos problemas ambientais urbanos, os parques também amenizam as tensões sociais, pois proporcionam um espaço de aproximação do ser humano com a natureza.

O primeiro benefício dos parques é a resistência à especulação imobiliária. Em 1858, Olmsted, autor do projeto do Central Park de Nova York, já falava sobre a importância de se ter delimitado uma grande extensão de terra para o parque, dizendo que "a totalidade da ilha de Nova York seria, não fosse essa reserva, dentro de muitos anos, ocupada por edifícios e ruas pavimentadas" (apud KLIASS, 1993, p. 22).

Outro benefício são os atributos estéticos dos parques, com ressalva para a importância da vegetação. Eles desempenham funções ligadas à satisfação sensorial e estética, como a diversificação da paisagem, o embelezamento da cidade e a amenização da aridez e da repetição dos prédios (GUZZO, [1997?]]; MAGALHÃES; CRISPIM, 2003).

Um terceiro benefício é o atendimento das necessidades de lazer e de recreação. A rotina cansativa imposta pela vida urbana pode ser atenuada por atividades realizadas nos parques, como caminhadas, passeios e brincadeiras, além da possibilidade de convivência entre os moradores nas cidades nesses espaços.

Esse benefício ligado ao lazer está também associado à função psicológica de aliviar o estresse. No entanto, as relações com respeito à saúde física e mental podem ser ainda mais profundas. Um experimento com pacientes em recuperação pós-operatória, publicado em 1984 por Roger S. Ulrich, constatou que a recuperação de pacientes que estavam em quartos com janelas voltadas para árvores foi mais rápida do que os que tinham vista para ambientes artificiais. Em trabalhos posteriores, foi observado que a própria presença de vegetação traz benefícios psicológicos, fisiológicos, cognitivos e comportamentais (MAGALHÃES; CRISPIM, 2003).

\section{Justificativas para o projeto}

- As profundas transformações ocorridas na sociedade brasileira nas últimas décadas parecem colocar os parques no foco das políticas públicas. Por um lado, as mudanças comportamentais iniciadas nos últimos trinta anos, revigoraram o uso dos parques ao aglutinar novos significados ao lazer e à recreação ao ar livre. Por outro lado, novos papéis têm sido atribuídos aos parques pelos diversos agentes envolvidos nos processos urbanos.

- Tem surgido grande número dos chamados parques ecológicos nas cidades que conciliam os usos de lazer da população com os objetivos de conservação dos recursos naturais, em geral de remanescentes de vegetação em áreas que estão sob impacto dos processos de urbanização. Porém só nos últimos anos vem se manifestando de modo mais consistente nas cidades brasileiras o uso dos parques como elementos de dinamização da economia urbana, especialmente das atividades ligadas ao lazer e ao turismo.

- A população da cidade de Teresina se encontra dissociada do rio e é preciso fazer uma melhor integração da cidade com ele, oferecendo opções de lazer público às suas margens, já que, em grande parte, elas se encontravam ocupadas por clubes particulares e residências, ou sem qualquer infra-estrutura que possibilitasse uma utilização mais efetiva.

- O local escolhido para o projeto de um parque urbano foi pensado de acordo com os seus prováveis usuários. A zona Leste de Teresina sofre uma carência muito grande com 
relação a espaços livres públicos urbanos e a avenida Raul Lopes está se tornando um eixo atrativo de lazer, seguindo-se então um vetor de crescimento urbano.

- O projeto em questão trata-se de uma estratégia que parte da premissa de que a conservação de tais espaços em áreas sob pressão dos processos de urbanização, só é viável se ela atrair e se mostrar útil à população que, a partir daí, passaria a defendê-lo de depredações, da especulação imobiliária e das eventuais invasões de seus espaços.

- A cidade de Teresina é conhecida nacionalmente por seu clima quente durante a maior parte do ano. Com a intensa urbanização, essa situação tende a ser agravada. É de suma importância, portanto, reservar espaços que agreguem uma boa arborização e bastante área de infiltração em meio a tanta pavimentação.

\section{6 - Objetivos}

\section{1 - Obejtivo geral}

Objetivo deste trabalho é elaborar um projeto arquitetônico e urbanístico de um parque urbano para a cidade de Teresina com equipamentos públicos de fins culturais cujo sentido seja servir de foco de atração para a comunidade, bem como a previsão de instalação de estabelecimentos privados com o fim de explorar e manter um espaço integrado e diversificado em suas funções. A idéia é a realização de um centro de convivência público para população, em uma região beneficiada por seus aspectos paisagísticos, procurando valorizar o bem natural mais importante que temos em nossa cidade: o rio.

\section{2 - Obejtivos específicos}

- Refletir a importância da paisagem para o planejamento urbano.

- Suprir uma carência de referenciais como este citado na cidade, propondo uma reorganização do espaço urbano da orla da avenida Raul Lopes e conseqüentemente da orla do rio Poti, incorporando-o à paisagem urbanística social da nossa cidade.

- Deslocar o centro atrativo dos shoppings centers, que descaracterizam a cidade pelo seu ponto de vista natural, mostrando para a população um conjunto de atividades de lazer que se pode realizar sem atrelar a isso o consumismo.

- Evocar a natureza, aliada ao lazer e recreação, além de proporcionar a dinamização da economia urbana e melhoria da imagem das cidades.

- Suprir uma carência de áreas verdes e recreativas públicas na zona leste da cidade, que dispõe quase que apenas de clubes particulares para atividades para atividades de lazer e recreação.

\section{7 - Fundamentação teórica}

\section{1 - Conceitos}

Desde o seu surgimento nas cidades, o parque tem assumido diferentes configurações e significados. Durante todo o século XX, especialmente a partir das décadas de 1960 e 1970, a velocidade das transformações econômicas, sociais e culturais acelera-se, imprimindo novos significados aos parques e exigindo que os profissionais de arquitetura e urbanismo revejam os pressupostos usados na definição do conceito de parque. 
No contexto brasileiro, em que a questão dos parques nunca recebeu a devida atenção, essa revisão reveste-se de importância, na medida em que, predomina a tendência de reduzi-lo a uma imagem, que em muitos casos, está superada. Esta situação tem dificultado a compreensão das novas funções que os parques têm assumido nas cidades.

Em descompasso com essa nova realidade, muitos profissionais de arquitetura e urbanismo continuam a conceituar os parques públicos com base no ideal do parque paisagístico do século XIX. Nessa visão, a paisagem pastoral criada por Frederick Law Olmsted no Central Park de Nova York - com seus extensos gramados, lagos e grandes massas de vegetação - hoje cercado de arranha-céus, seria o protótipo do parque público.

Um estudo dos mais variados conceitos de parque no Brasil e no mundo irá nos fazer perceber sutis diferenças que muitas vezes os torna completamente longe de qualquer semelhança tanto na sua forma física quanto nas funções que neles se realizam.

\section{Parque urbano}

Segundo Macedo um parque urbano é um espaço livre público estruturado por vegetação e dedicado ao lazer da massa urbana, que atende a uma grande diversidade de solicitações de lazer, tanto esportivas quanto culturais, não possuindo, muitas vezes, a antiga destinação voltada basicamente para o lazer contemplativo.

Sá Carneiro afirma que parques urbanos são espaços livres públicos com função predominante de recreação, ocupando na malha urbana uma área em grau de equivalência superior à da quadra típica urbana, em geral apresentando componentes da paisagem natural.

O autor Sakata considera parque urbano todo espaço de uso público destinado à recreação de massa, qualquer que seja seu tipo, capaz de incorporar intenções de conservação e cuja estrutura morfológica é auto-suficiente, isto é, não é diretamente influenciada em sua configuração por nenhuma estrutura construída em seu entorno.

\section{Parque ecológico ambiental}

Macedo conceitua parque ambiental de acordo com seu objetivo prioritário: a conservação desse ou daquele recurso ambiental, como um banhado ou um bosque. $E$, paralelamente, diz que possui áreas muito concentradas voltadas para atividades de lazer ativo ao lado de áreas voltadas para o lazer contemplativo.

\section{Parques temáticos}

Para parques temáticos a definição de Macedo vai de encontro com a maioria dos autores, por se tratar de um tipo bem específico de parque: forma de lazer atualmente popular na qual, paralelamente a uma cenarização extrema, representativa de lugares reais ou imaginários, se pratica uma atividade intensa de lazer eletrônico dentro de edifícios. Em geral, os brinquedos simulam histórias ou passeios no tempo, na técnica ou no espaço. Esse tipo de parque quase sempre pertence à iniciativa privada, sendo comumente encontrado junto às grandes aglomerações urbanas.

\section{Praças}

24 Já o conceito de praças, mais facilmente definido, é defendido por Sá Carneiro como espaços livres públicos, com função de convívio social, inseridos na malha urbana como elemento organizador da circulação e de amenização pública, com área equivalente à da quadra, geralmente contendo expressiva cobertura vegetal, mobiliário lúdico, canteiros, bancos. 


\section{Faixas de praia}

Sá Carneiro define também faixa de praia como sendo espaço livre com raio de influência metropolitana que se desenvolve na área litorânea, com vegetação predominante de coqueiro, podendo conter tanto equipamentos de esportes quanto de lazer contemplativo.

\section{Margens de rios}

Finalmente analisamos a definição de Sá Carneiro para margens de rios: espaços livres linearmente dispostos junto aos corpos d'água que lhes servem de delimitação, sendo propícios para receber cobertura vegetal.

Como se percebe, o papel do parque no Brasil é abrangente e sua definição nem sempre precisa. Muitas vezes espaços de lazer de pequeno porte são denominados parques apenas porque são cercados, contém instalações de lazer e alguma vegetação.

Outras denominações, assim como podemos ver acima, se bem analisadas, enquadram-se também em um ou outro conceito de parque, o que significa que um pode estar contido no outro.

Para este trabalho será considerado um espaço livre na cidade maior que a dimensão de uma quadra, que se encontra separado da "margem de rio" apenas por uma avenida. Este espaço terá como estrutura uma cobertura vegetal mista com componentes da paisagem natural e uma ampla área pavimentada dedicada ao lazer ativo da população.

\section{2 - Parques em Teresina}

"O verde exuberante que te veste": esse é um dos versos do hino de Teresina, que ressalta a predominância do verde na cidade.

Teresina possui vários parques, praças e bosques, um total de área verde de $13 \mathrm{~m}^{2} / \mathrm{hab}$., superando o valor de referência da ONU que é de $12 \mathrm{~m}^{2} / \mathrm{hab}$.

Estes espaços livres de edificações, se observarmos bem, não são igualitariamente distribuídos pela cidade. Alguns bairros, especialmente os mais centrais da cidade estão sendo tão edificados e pavimentados que as áreas verdes e livres estão cada vez mais restritas.

Podemos observar esta situação na referida zona em questão do projeto, a zona leste da capital. Com exceção da orla do rio Poti, a qual trata-se apenas de uma reserva praticamente intocável de espécies nativas, a região não conta com nenhum grande espaço livre público de lazer arborizado.

A cidade de Teresina possui uma boa quantidade de parques, porém na sua grande maioria são apenas parques ambientais, com poucas atividades voltadas ao lazer ativo, ou, em muitos casos, nenhum equipamento que possa ser considerado atrativo pela população. A falta dessa infra-estrutura, até mesmo a falta de uma iluminação provoca um afastamento dos possíveis usuários destes espaços, atraindo pessoas para outros tipos de atividades como caça, uso de drogas, atos de vandalismo e violência.

\section{8 - O projeto em questão}

\section{1 - Contextualização da área em estudo}

O Parque urbano definido neste projeto situa-se na zona Leste da cidade de Teresina, em um terreno localizado em frente à avenida Raul Lopes, via essa que margeia o rio Poti. Este rio separa a zona leste da zona centro/norte, tornando suas margens áreas de intensa valorização. Essa valorização das margens do rio Poti, em especial na área mais central da malha urbana 
ocorreu devido a uma especulação imobiliária crescente para moradias (edificações). Em seguida com a construção dos shopping centers praticamente às margens do rio, essa procura pela proximidade aumentou, de forma que o fluxo de tráfego se torna cada vez mais intenso nesta região. A avenida Raul Lopes se tornou uma via que liga centro/sul ao norte/leste de Teresina. Devido à saturação de tráfego das demais vias, esta avenida, maior e melhor equipada, tem se tornado uma veia essencial da malha urbana da cidade atual. Localizada entre duas pontes que ligam o centro/leste e o norte/leste da capital, a tendência é o aumento do fluxo de pessoas que utilizarão a avenida. Além das duas pontes existentes, uma outra ponte está sendo construída no meio desta avenida, para melhor distribuir o fluxo de veículos que se dirige em direção ao centro da cidade, local onde muitos teresinenses trabalham. Com a construção desta nova ponte a valorização e especulação imobiliária dos terrenos que margeiam o rio será ainda maior, gerando uma área conurbada e de intensa pavimentação. Daí a necessidade de preservação de uma área verde associada ao lazer nessas imediações.

Observando o mapa da cidade (Figura 2) podemos perceber que a zona leste de Teresina possui uma carência de áreas verdes e públicas - recreativas, o que é de fundamental importância para o bom funcionamento físico-social de uma cidade, como foi defendido em tópicos anteriores.

O terreno escolhido, além de estar numa área que propicia a preservação de espécies nativas, a cultura e o lazer, está em meio a um fluxo de acessos de forma que todas as grandes e importantes vias da região podem escoar para ele.

Analisando ainda o seu entorno podemos perceber uma grande zona residencial de alto padrão da cidade, as ZR2, ZR3 e ZR4. Bairros de classe média alta que têm como praticamente única opção de lazer os shoppings centers da cidade. Além disso, somente restaurantes, bares, boates e clubes particulares.

A concretização do um projeto que vise a preservação e a inserção de um espaço livre público de lazer ativo e contemplativo se torna essencial para o bem estar da população que habita a região e a própria cidade como um todo. Torna-se essencial também se analisarmos o ponto de vista paisagístico do entorno do rio. Ao lado de uma margem protegida pela legislação municipal como área de preservação total das espécies vegetais, encontramos dissociadas imagens de intensas edificações em constante crescimento. Dessa forma o parque urbano tem o papel também de unificar o conjunto paisagístico da orla do rio ao de sua proximidade e se tornar uma barreira para o crescimento acelerado no processo de urbanização e especulação imobiliária de uma área já quase saturada.

\section{2 - O terreno}

O terreno escolhido para o projeto tem aproximadamente 12 hectares e está situado nos limites das vias: avenida Raul Lopes, avenida Universitária, avenida Coronel Costa Araújo e rua Agostinho Alves (Figura 3). Limita-se também com áreas residenciais e comerciais.

É uma área que possui vários lotes particulares. Não está sendo usufruída por nenhum proprietário, ficando praticamente abandonada. Possui uma região de intensa densidade vegetal, com arvores de grande e médio porte, de tipos variados (Figura 4).

\section{3 - Temas e programas de necessidades}

O parque urbano proposto para a cidade é uma tentativa de integração da população diretamente com o meio natural. Interagindo com a natureza, tirando proveito do bem estar que ela pode lhe promover, espera-se que a população passe a gostar e preservar o bem natural. 
Uma mistura perfeita de lazer ativo e contemplativo é o que se espera como resultado do projeto, pois cada área foi pensada com um objetivo específico e um estudo de fluxos estudado minuciosamente para o perfeito ciclo de atividades.
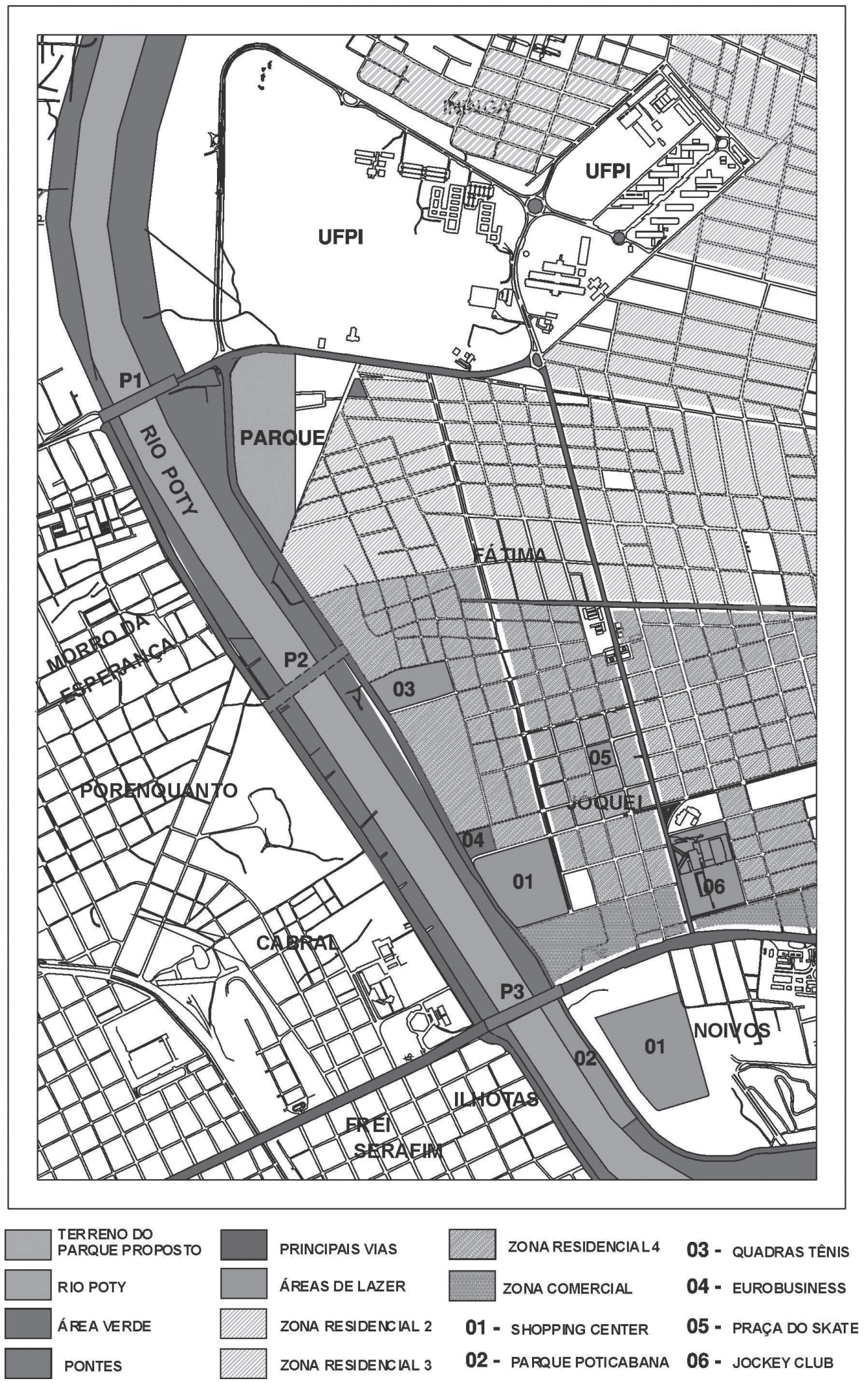

Figura 2: Mapa de parte da cidade de Teresina, situando a área em estudo

Fonte: Desenho do mapa da cidade de Teresina, Secretaria Municipal de Planejamento.

Adaptações: Liz Ivanda Evangelista 


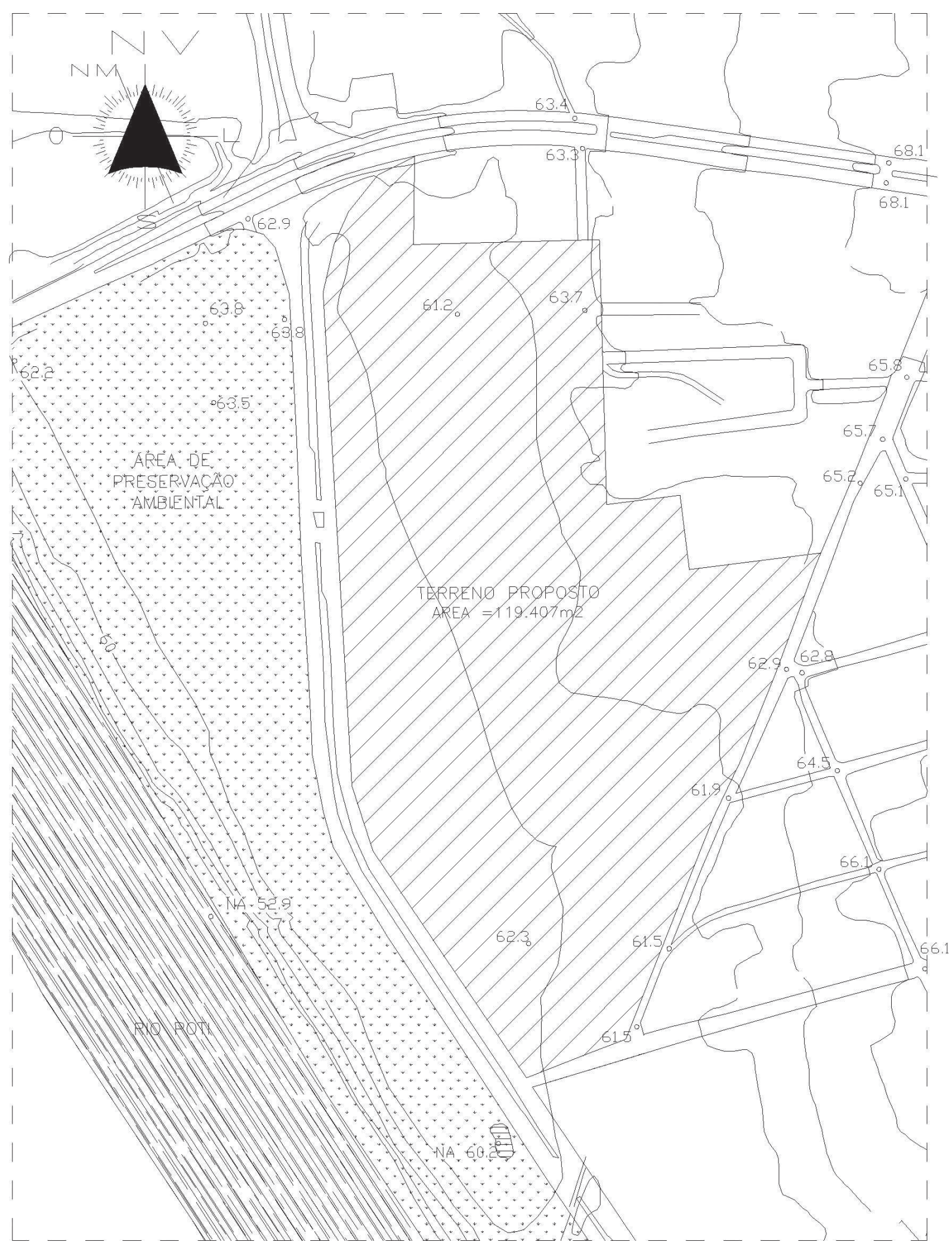

Figura 3: Planta de situação do terreno

Fonte: Imagem do arquivo pessoal, abril de 2006 


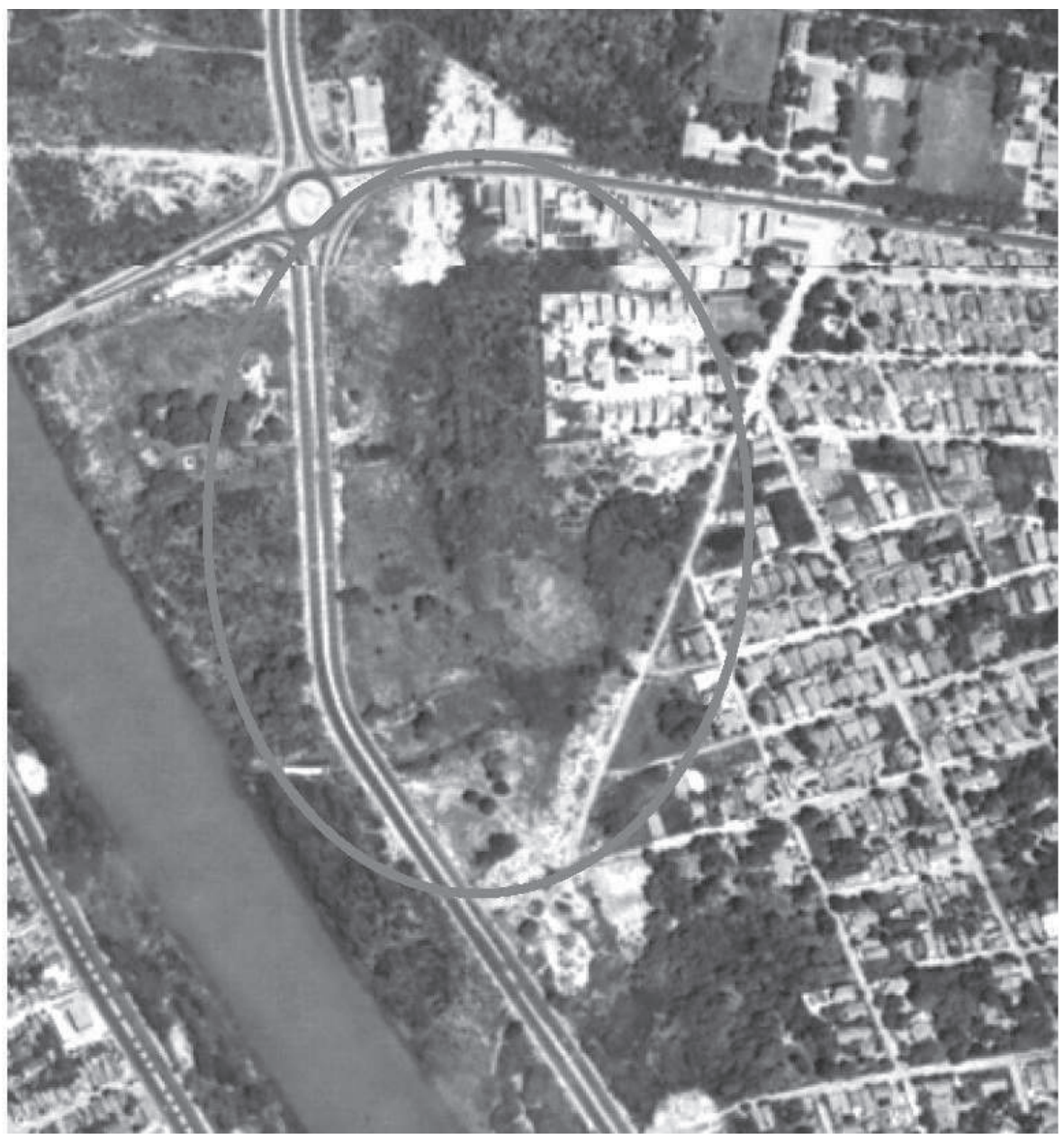

Figura 4 - Fotografia aérea do terreno

Fonte: Secretaria Municipal de planejamento - Prefeitura de Teresina

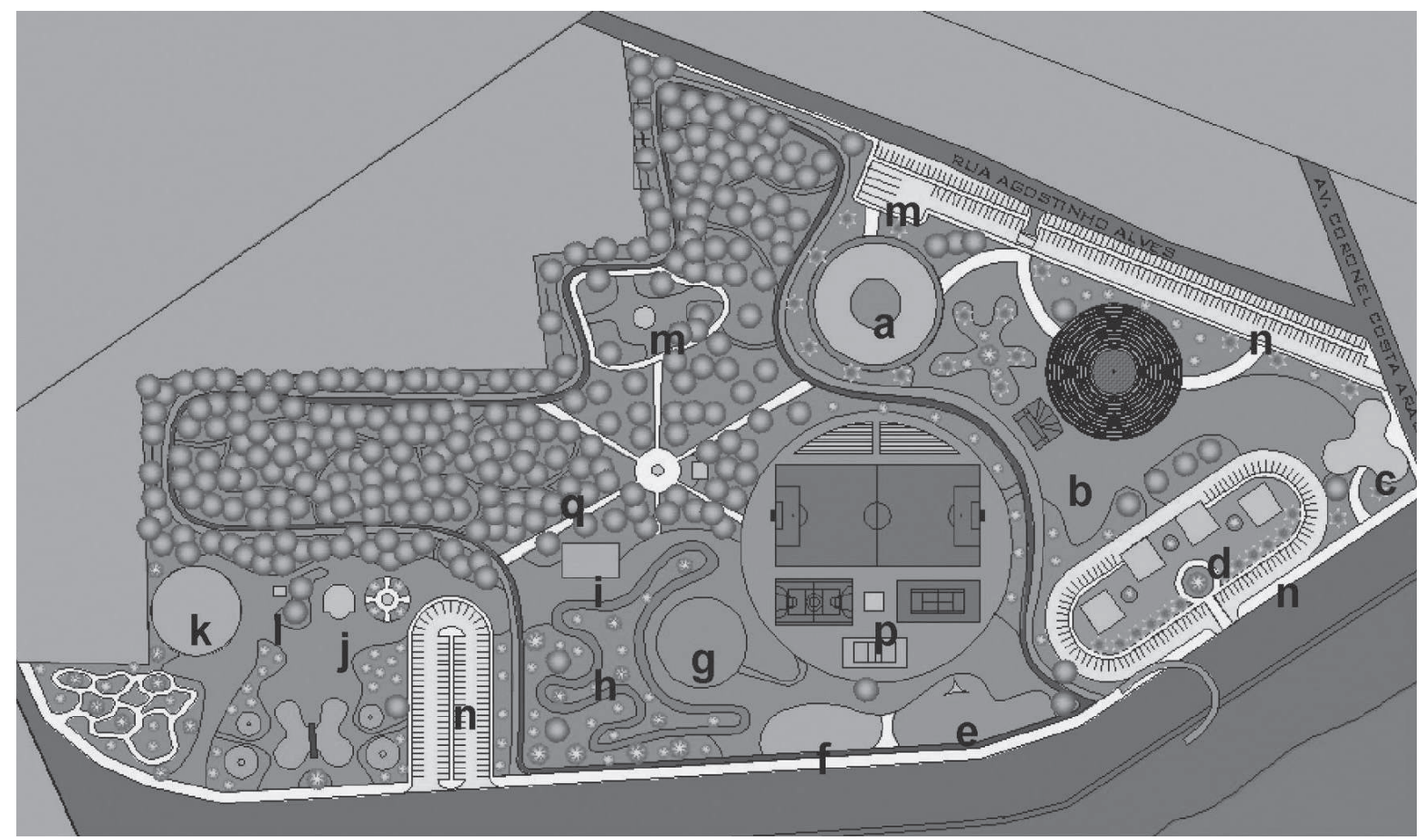

Figura 5: Planta geral do parque

Fonte: Imagem do arquivo pessoal, abril de 2006 
Programa de necessidades (Figura 5)

1 - Pavilhão de Feiras e Exposições

2 - Concha Acústica

3 - Entrada Principal/Administração

4 - Restaurantes

5 - Palco

6 - Equipamentos Ginástica

7 - Pista de Skate

8 - Pista de Bicycross

9 - Academia dos cães

10 - Capela

11 - Ciranda das Crianças

12 - Banheiro Público

13 - Mirante

14 - Estacionamento para carros

15 - Estacionamento para ônibus

16 - Secret. Municipal Esporte e Lazer

17 - Guarda Verde

18 - Arquibancada/Vestiários

19 - Passarela

20 - Caminho dos Namorados

21 - Trilha da Poesia

22 - Coreto

23 - Quadras de Esportes

\section{4 - Parque das Artes Beira-Rio}

Como o principal objetivo do projeto era unir o lazer da população à preservação ambiental das áreas verdes que ainda restam na cidade, procurou-se valorizar e permanecer com o máximo possível das árvores existentes. Toda a parte pavimentada foi projetada em cima da região não arborizada do terreno, como podemos observar na sobreposição da fotografia aérea do terreno com o projeto do parque (Figuras 6 e 7 ).

O parque é de certa forma temático, se subdividindo em algumas praças (Figura 8). Logo na entrada principal localiza-se a parte administrativa e informativa, onde deverá conter um toten com o mapa do parque para vista de todos. Os estacionamentos foram zoneados de acordo com a necessidade de cada área. Para o espaço da cultura (Disco da cultura), onde fica a concha acústica e um espaço para feiras de artesanato, juntamente com o pavilhão para grandes feiras e exposições foram oferecidas cerca de 170 vagas de estacionamento, além de cinco vagas para ônibus de excursões turísticas ou carros de grande porte.

Na praça de alimentação também há o estacionamento próprio. Totalizando quatro restaurantes, a idéia é que sejam oferecidas cozinhas temáticas: chinesa, italiana (massas), comidas típicas do nordeste e uma choperia.

Na praça do esporte, um campo de futebol, uma quadra poliesportiva, uma quadra de tênis e uma quadra de vôlei de praia. As arquibancadas servem também de cobertura para os vestiários feminino e masculino. Outro esporte bastante valorizado na cultura teresinense é o skate, não 

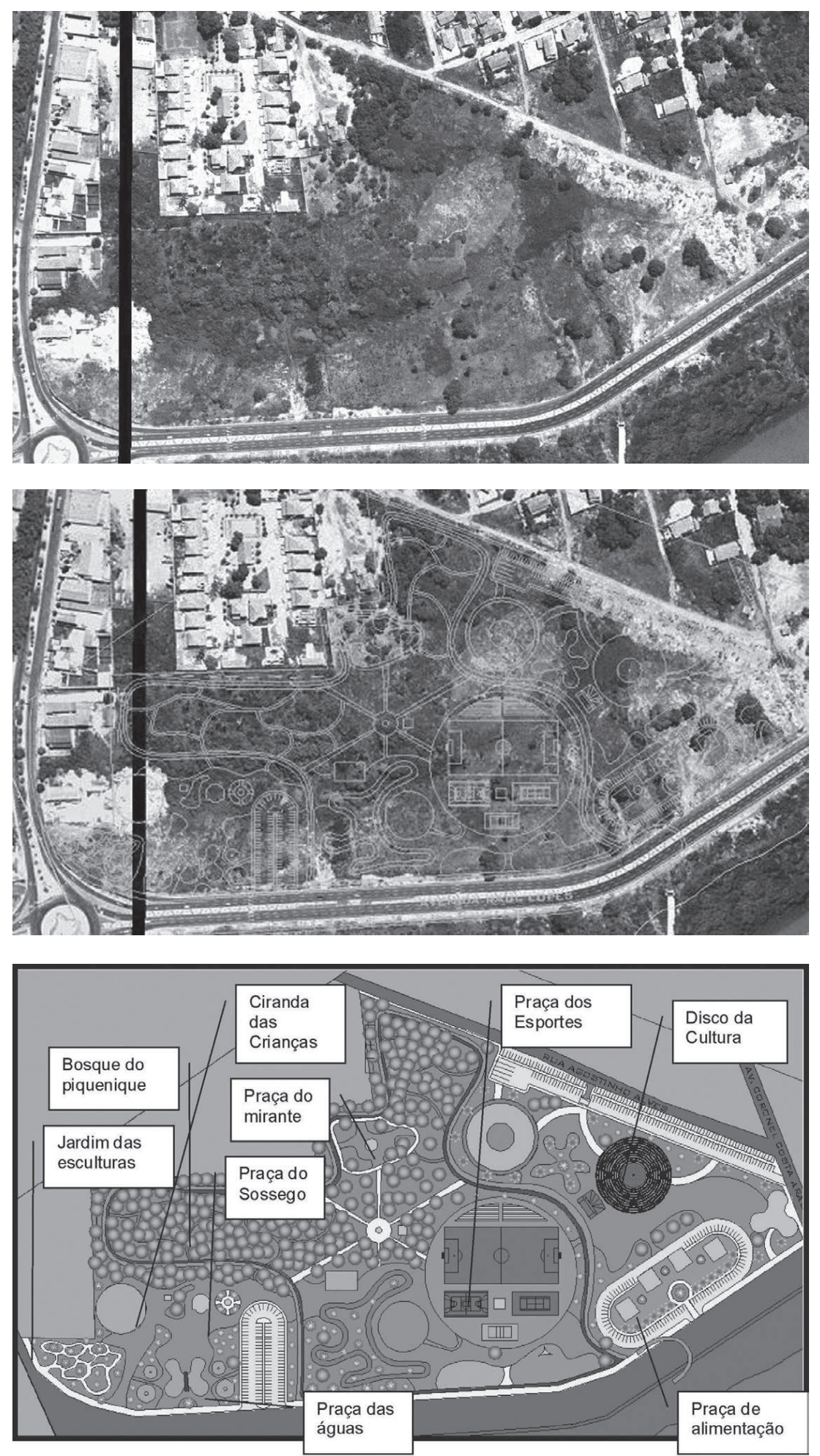

Figura 6: Foto aérea do terreno

Figura 7: Sobreposição do projeto no terreno

Figura 8 - Planta geral do parque

Fonte: Imagem do arquivo pessoal, abril de 2006

podendo deixar de ser projetada uma pista para os skatistas. Além do skate, o bicycross vem ganhando bastante espaço em Teresina e há uma carência de espaços para treinar este tipo de esporte. Torna-se necessário uma pista no parque, tendo em vista o crescimento do número de competições no setor. Para a administração do esporte foi destinado um apoio para a Secretaria Municipal do Esporte e Lazer - SEMEL. É importante mantê-la para a organização e preservação dos equipamentos, assim como a guarda dos materiais como bolas, redes, etc. Outro espaço curioso que foi criado no parque é a academia dos cães. Um local para treinar cachorros, em especial. Muitas pessoas saem nas ruas para passear com seus cães e sentem falta de um local como este para treinar os animais, em especial numa área nobre como esta. 
Foi criado também um local para alongamento e ginástica. Além de ser uma avenida tradicionalmente conhecida pela prática do cooper, o parque possui uma pista de cooper e uma ciclovia próprios. Outro espaço inserido foi um local para a prática da ginástica aeróbica, na margem da pista, um palco tipo tenda tencionada chama a atenção de quem passa caminhando para aulas de ginástica periódicas.

Ainda na margem da pista, logo após a praça dos esportes, outro estacionamento destinado a esta área. Em seguida criou-se um espaço meramente contemplativo: A praça das Águas e o jardim das Esculturas. Pela praça das Águas podemos encontrar espelhos d'água com ponte de madeira e fontes jorrantes. A idéia é criar um clima agradável a quem passa e convidar as pessoas a entrarem no parque. No jardim das Esculturas, por caminhos propositadamente labirínticos, as pessoas são levadas a admirar esculturas de artistas da terra, procurando valorizar o que é nosso.

Ao penetrarmos no parque encontramos ainda a Ciranda das Crianças, grande círculo de areia com brinquedos diversos e alternativos, infantis e a praça do Sossego, espaço tranqüilo, com amplos jardins e sombreamentos, para quem quer curtir a paz. Nela fica a capela do parque e um espaço para idosos curtirem a terceira idade, com mesinhas para jogos de fim de tarde.

Mais ao fundo, numa área bastante arborizada, que exige uma preservação das espécies, foi proposto um bosque, o Bosque do Piquenique. Nada melhor do que aproveitar a sombra de árvores nativas para curtir a prática do piquenique.

Alguns caminhos foram traçados para facilitar a circulação das pessoas por dentro das reservas do parque. Alguns desses caminhos foram designadas funções, para tornar mais interessante o traslado. Por exemplo, temos o Caminho dos Namorados, onde bancos e caramanchões se espalham aconchegantemente; a Trilha da Poesia, onde painéis com poesias escritas se espalham ao longo da caminhada e a Trilha do Silêncio, mais reservada e tranqüila, que leva todos à praça do Mirante. Como ponto de encontro de todos esses caminhos criou-se uma pequena pracinha com um coreto. Lá também localiza-se a Guarda Verde, posto policial que vigia o parque.

Na praça do Mirante encontramos uma área aberta em meio a um bosque, onde podemos, através do Mirante, com cerca de dez metros de altura, observar todo o parque.

Por fim, percorrendo e circulando o parque traçou-se uma pista de cooper e uma ciclovia, que se encontram com o calçadão, tornando um só ente Calçadão - pista de cooper.

Uma passarela foi projetada a fim de promover a ligação do parque com a margem do rio, visto que também é uma área de preservação ambiental. A intenção é atrair as pessoas que fazem suas caminhadas na beira-rio para adentrar ao parque, assim como convidar as pessoas que estão usufruindo o parque para percorrer e conhecer a margem do rio. Tornou-se necessário a passarela devido ao intenso tráfego da avenida, que tende a aumentar com o passar dos anos. Além de servir como meio de atravessar a pista, a passarela vincula o calçadão da beira-rio à pista de cooper do parque fazendo com que se torne um passeio único.

Para promover uma integração maior ainda entre o parque e o rio, foi projetado um píer, local destinado ao contato direto das pessoas com paisagem e a água.

Dessa forma, o parque foge do comum e atravessa a fronteira do processo de intensa urbanização que vem passando a cidade de Teresina, colaborando para o bem-estar dos seus moradores e promovendo a aproximação dos mesmos com a natureza. 


\section{Anexo}

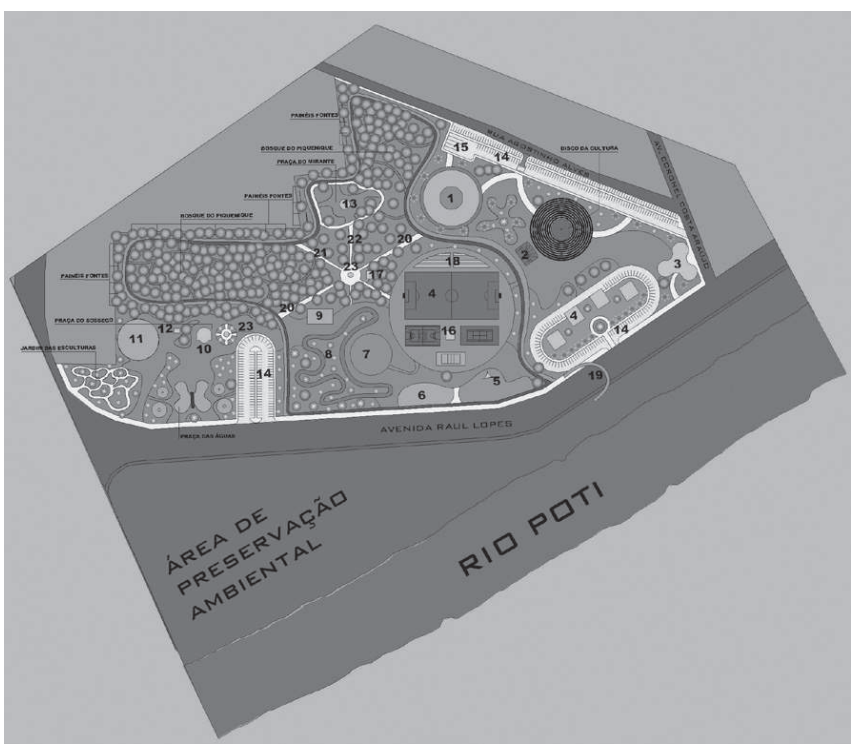

Projeto para o Parque Urbano Público Municipal de Teresina - Parque das Artes Beira-Rio

\section{Bibliografia}

BARCELLOS, Vicente Quintella. Os novos papéis do parque público: O caso dos parques de Curitiba e do Projeto Orla de Brasília [2000?].

BARTALINI, V. Áreas verdes e espaços livres urbanos. Paisagem e Ambiente: Ensaios, São Paulo, n. 1, p. 49-54, 1986.

BONGESTABS, Domingos H. Universidade Livre do Meio Ambiente. In: Visões da paisagem: Um panorama do paisagismo contemporâneo no Brasil. São Paulo: ABAP - Associação Brasileira de Arquitetos Paisagistas, 1997.

COLEÇÃO PAISAGISMO. 1 SEMINÁRIO de Arborização Urbana no Rio de Janeiro. Rio de Janeiro: EBA, v. 1, 1997.

ENCICLOPÉDIA Mirador Internacional. São Paulo: Encyclopaedia Britannica do Brasil, 1987.

EVANGELISTA, Rosana Mendes. Parques urbanos e educação ambiental: O caso do Parque Ecológico Águas Claras. 2005. Lato Sensu em Educação Ambiental (Doutorado) - Universidade Católica de Brasília, Brasília, Distrito Federal, 2005.

GALENDER, Fany. Considerações sobre a conceituação de espaços públicos. Paisagem e Ambiente: Ensaios, São Paulo: FAUUSP, n. 4, p. 133-120, 1992.

KLIASS, Rosa Grena. Os parques urbanos de São Paulo. São Paulo: Pini, 1993.

MACEDO, Silvio Soares. Quadro do paisagismo no Brasil. São Paulo: Edusp/Imprensa Oficial de São Paulo, 2002.

MACEDO, Silvio Soares; SAKATA, Francine Gramacho. Parques urbanos no Brasil. São Paulo: Edusp/Imprensa Oficial de São Paulo, 2002.

MAGALHÃES, Luís Mauro; CRISPIM, Angela Alves. Vale a pena plantar e manter árvores e florestas na cidade ciência? Ciência Hoje, v. 33, n. 193, p. 64-68, maio 2003.

MENEGAT, Rualdo. Cidades sustentáveis: A conferência da ONU. Zero Hora. Porto Alegre, p. 16, 12 out. 2005. Disponível em: < http://triplov.com/3v/index.php?p=1022>. Acesso em: 24 out. 2005.

PAISAGEM E AMBIENTE: Ensaios - São Paulo: FAUUSP, 1997.

ROBBA, Fabio; MACEDO, Silvio Soares. Praças brasileiras. São Paulo: Edusp/Imprensa Oficial de São Paulo, s/d.

SÁ CARNEIRO, Ana Rita; MESQUITA, Liana de Barros. Espaços livres do Recife. Recife: Prefeitura da Cidade do Recife/Universidade Federal de Pernambuco, 2000.

SCALISE, Walnyce. Parques urbanos: Evolução, projeto, funções e uso. Revista Assentamentos Humanos, Marília, v. 4, n. 1, p. 17-24, out. 2002.

SUPERINTENDÊNCIA de Desenvolvimento Urbano da Região Leste de Teresina - SDU. 